\title{
Uusi leikkuulaite kuitukasvien niittoon
}

\author{
Kalle Kautto \& Antti Pasila \\ Helsingin yliopisto, Maa- ja kotitalousteknologian laitos, PL 27 (Viikki F, Latokartanonkaari 13) \\ 00014 Helsingin yliopisto \\ E-mail: kalle.kautto@helsinki.fi, antti.pasila@helsinki.fi
}

Suomessa kasvien korjuuolosuhteet ovat syksyllä vaikeat johtuen kosteudesta. Sadonkorjuu niittämällä on hankalaa, koska kasvit ovat sitkeitä suuren kosteusmäärän ansiosta. Toisten kuitukasvien korjuu voidaan tehdä keväällä, jolloin korjuuolosuhteet ovat kuivemmat. Kevät näyttäisi olevan paras ajankohta kuituhampun korjaamiseksi. Tällöin kuitumateriaali on kuivaa ja helposti prosessoitavissa. Lisäksi kevätkorjuu tarjoaa taloudelliset mahdollisuudet myös kuidun tuottamiseksi teollisuuden raaka-aineeksi.

Olemassa olevat kuitukasvien korjuuteknologiat perustuvat perinteisiin heinänkorjuukoneisiin ja leikkuupuimurin käyttöön. Teknologioiden kehittymisestä huolimatta kuitukasvien kohdalla korjuun ongelmia ei ole pystytty vielä ratkaisemaan muutoin kuin kasvien korjaamisella nyhtömenetelmällä. Tosin on kehitetty myös pellavaprosessoreita, jotka prosessoivat pellavan vartta jo korjuun yhteydessä. Tässä korjuuprosessissa siemenet saadaan talteen sekä tämän lisäksi prosessoriin on asennettu loukutuslaite ja paalain, päistäreet pudotetaan takaisin pellolle. Tämäntyyppiset koneet tuottavat vain esikäsiteltyä pellavakuitua, mutta lisäksi tarvitaan myös eri tuotteisiin erikoistuneita jatkokäsittelylaitoksia (Pasila et al. 1998).

Erityyppiset kasvilajit vaativat erilaisen teränopeuden. Esimerkiksi viljakasveille riittää nykyinen terägeometria sekä teränopeus. Sormipalkkiterän keskimääräinen leikkuunopeus viljoille ja karkeille heinäkasveille on $1,5 \ldots 1,7 \mathrm{~m} / \mathrm{s}$. Kuitukasveja korjattaessa täytyy terän nopeutta kasvattaa johtuen korren erilaisesta koostumuksesta. Kuitukasveilla korsi on sitkeämpää ja vaikeammin leikattavissa. Hamppua keväällä korjattaessa kuitu tukkii perinteisen sormipalkkiterän ja terä pysähtyy täysin. Talven aikana kuitu irtoaa korresta, mikä muodostaa hyvin sitkeän ja vaativan leikattavan materiaalin. Uudentyyppisen, leikkuuteholtaan suuremman terälaitteen tarpeellisuus on tullut kenttäkokeissa ilmi (Pasila et al. 1998).

\section{Normaalin leikkuupöydän modifiointi}

Ensimmäisessä vaiheessa modifioitiin leikkuupuimurin leikkuupöytää siten, että teränopeutta kasvatettiin $40 \%$ sekä pöydän yläpintaan kiinnitettiin teflonkangas kitkan pienentämiseksi. Tehdyt muutokset oleellisesti paransivat pöydän toimivuutta kuitupellavaa korjattaessa. Ongelmaksi muodostui teränkäytön alimitoitus, jota ei ollut suunniteltu teränopeuden kasvattamista silmälläpitäen. Kuormitukset kasvoivat niin suuriksi, että alkuperäinen teräkampiakseli ei kestänyt suurentuneita massavoimia.

Kartoitettaessa jatkokehittelyyn valittavan terälaitteen toimintaperiaatteen valintaa tehtiin esitutkimuksia kahdella erityyppisellä koekonekonstruktiolla. Tätä varten esiselvitystyönä valmistettiin sekä ketjumainen leikkuuterätyyppi sekä toinen rinnakkaisterätyyppi vannesahaterästä. Näiden tarkoituksena oli todentaa toimintaperiaatteiden toimivuus käytännön kenttäolosuhteissa sekä selvittää, millainen täyden mittakaavan leikkuupöydän konstruktion tulisi olla. Ketjuterän testauksessa leikattavina materiaaleina käytettiin kevätkorjatun kuituhampun sekä syksyllä nyhdetyn kuitupellavan varsia.

\section{Täyden mittakaavan leikkuulaite}

Koelaitekokeilujen pohjalta jatkokehitettäväksi teräperiaatteeksi valittiin vannesahaan perustuva konstruktio. Tutkimuksessa käytettiin Sampo Rosenlew 2055 -leikkuupuimurin uutta leikkuupöytää, johon leikkuulaite rakennettiin. Leikkuupöydän työleveys on 10,5 jalkaa $(3150 \mathrm{~mm})$. Vannesahan sovittaminen leikkuupöytään ratkaistiin palauttamalla terä yläpuolisen kehikon kautta kääntöpyörien kautta sormipalkille. Rakenne muodostui kuvan 1 mukaiseksi. Leikkuulaite on rakenteeltaan 
samantyyppinen kuin prototyyppikin, ainoastaan suurennettu siitä sopimaan leikkuupöydän rakenteisiin sopivaksi. Rakennemateriaalit sekä rakenteen tuentavaatimukset muuttuivat oleellisesti. Palkkimateriaalina käytettiin neliöputkipalkkia. Kulmatuenta ja säädöt saatiin parhaiten toteutettua levyosilla. Leikkuupöytään kiinnitettävät kannatinpalkit on hitsattuna leikkuupöydän sivulevyihin. Sormet ja taittopyörät on kiinnitettyinä leikkuulaitteessa yläpalkkiin ja sivupalkkeihin. Terän ohjaus tehdään sekä sormien, teräohjainten sekä taittopyörien avulla. Taittopyöriin on jyrsitty urat terälle.

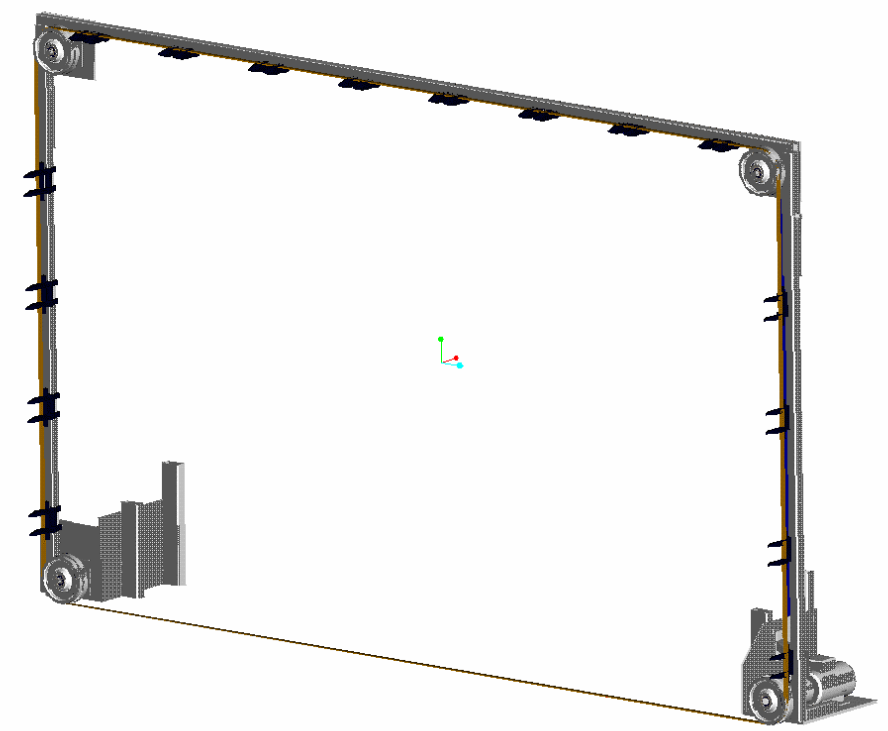

Kuva 1. Vannesahaan perustuva leikkuulaite. Leikkuulaite asennettiin leikkuupöytään vastaavalle kohdalle kuin sormipalkkiterä sijaitsee. Terä kulkee taittopyörien urissa ja sormiparein tuettuna. Teränopeus suurimmillaan on noin $46 \mathrm{~m} / \mathrm{s}(\mathrm{n} .160 \mathrm{~km} / \mathrm{h})$ ja työleveys 10,5 jalkaa $(3150 \mathrm{~mm})$. Leikkuulaitteen maksimileveys on $3650 \mathrm{~mm}$ ja korkeus $2200 \mathrm{~mm}$.

Kehän korkeuden suuruuden aiheuttaa kaatokelan liikeradan säilyttäminen. Riittävän pitkän korren ollessa kyseessä korsien kietoutuminen kaatokelaan on vaarana, jos kelaa ei pysty säätämään riittävän ylös. Työleveys on koko pöydän leveydeltä, mutta kokonaisleveys muodostuu suuremmaksi, koska alataittopyörät joudutaan jättämään pöydän sivulevyjen ulkopuolelle konstruktiivisista tekijöistä johtuen.

\section{Vannesahaterän mittaustulokset}

Alustavissa kokeissa "päättymättömän" terän tehontarve on osoittautunut ratkaisevasti pienemmäksi kuin perinteisen sormipalkkiterän tehontarve. Leikkuupöydän terälaitteen teho saadaan hydrauliikkajärjestelmästä, jolle välitetään voima pöytää käyttävältä hihnalta (leikkuupöydän ensiöakselilta). Hydrauliikkajärjestelmä on itsenäinen ainoastaan terää käyttävä systeemi, eikä ole yhteydessä leikkuupuimurin ajo- tai työhydrauliikkaan. Tehontarvemittaus tehtiin hydrauliikkajärjestelmästä anturilla, jolla voidaan mitata järjestelmän paine, tilavuusvirta sekä hydrauliikkaöljyn lämpötila.

Hydrauliikkajärjestelmän lämpötila mitattiin, jotta viskositeetin muutoksen vaikutus voidaan ottaa huomioon pumpun ja moottorin toiminta-arvoissa. Mittaustuloksia verrattiin perinteisen teräpalkin tehontarvearvoihin. Vakolan koetilalla on tehty mittaussarja, jossa selvitettiin perinteisen leikkuupöydän terän tehontarvetta öljypellavan puinnissa. Mittaustulokset kerättiin käyttämällä automaattista keruulaitetta, joka kirjasi pulssilaskurin lukeman sekä paineen jännitesignaalin sekä RTD -metallivastusanturilta saatavan lämpötilasignaalin. Kuvassa 2 on esitettynä vannesahaterän tehontarvetulokset ja hydrauliikkajärjestelmän öljyn lämpötila ajonopeuden suhteen. 


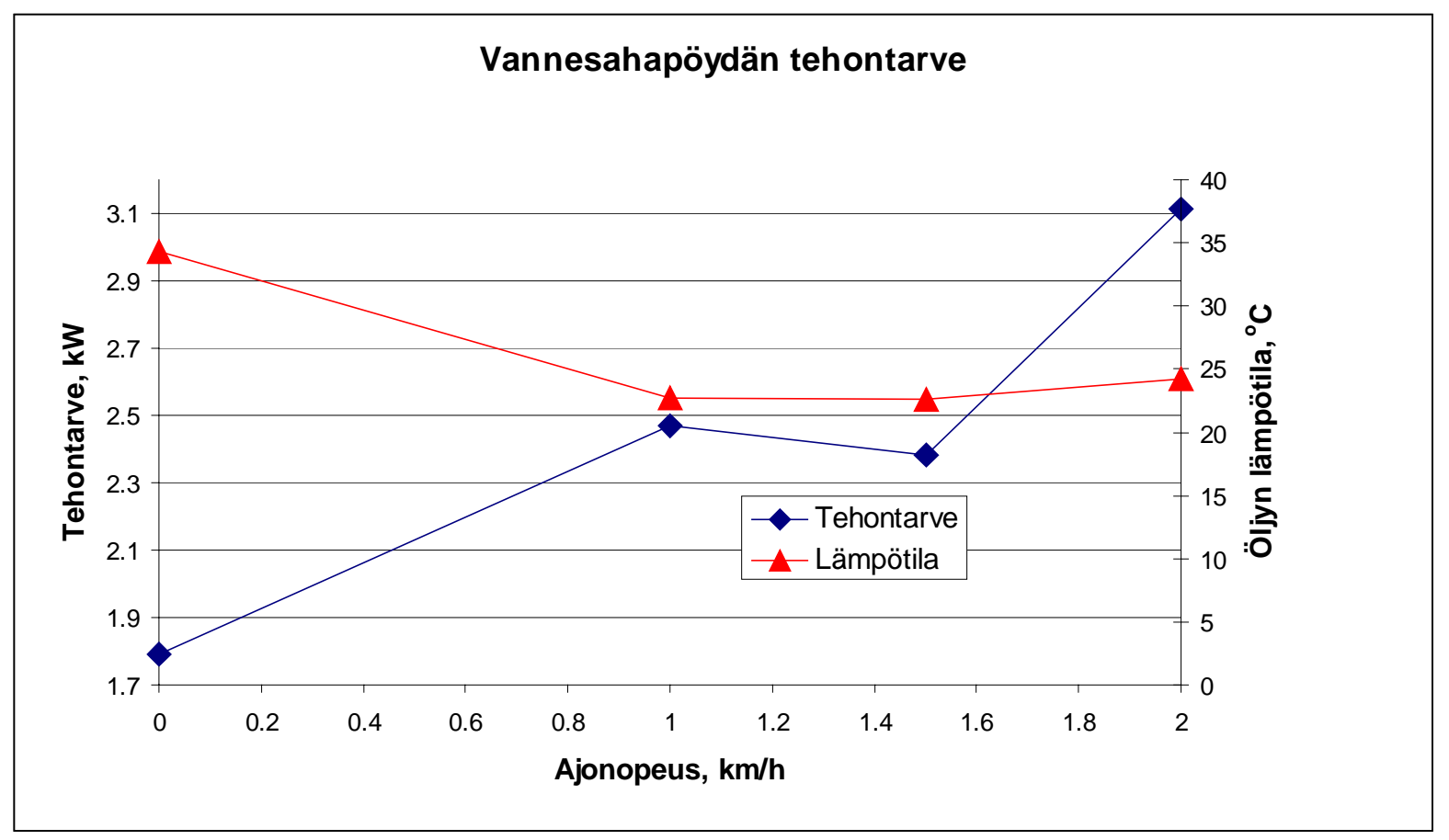

Kuva 2. Vannesahaterän tehontarve. Tehontarve ja hydrauliikkajärjestelmän lämpötila puintikokeissa. Puitavana materiaalina oli kuitupellava Sigganssin koetilalla syksyllä 1999. Leikkuupöydän työleveys oli 10,5 jalkaa.

Keskimääräinen tehontarve vannesahaterällä (kuva 2) sijoittuu noin 2,6 kW:iin $\quad(0,9 \mathrm{~kW}$ työleveysmetriä kohden) ajonopeudesta riippuen. Mittaustuloksiin vaikuttavat sekä leikkuugeometria ja terägeometria sekä suurimpana tehontarpeen aiheuttajana käytetyn sormiratkaisun, tässä tapauksessa vastaterän toimintaperiaate. Viskositeetin muutokset hydrauliikkajärjestelmässä ovat välillä $200 \ldots 80$ cSt, joka ei suuresti vaikuta moottorin hyötysuhteeseen, joka on tällöin 87 \%.

Näitä mittaustuloksia verrataan tavallisen sormipalkkiterän vastaaviin tuloksiin, jotka on saatu puimalla öljypellavaa Vakolan koetilalla (kuva 3). Tässä kokeessa mittausjärjestelmä oli toteutettu siten, että terälaitteen kiertokankeen oli kiinnitettynä venymäliuskat, joilla mitattiin terävoimia. Kokeessa keskimääräinen teränopeus normaalilla sormipalkkiterälaitteella leikkuupuimurissa oli noin $1,3 \ldots 1,5 \mathrm{~m} / \mathrm{s}$. 


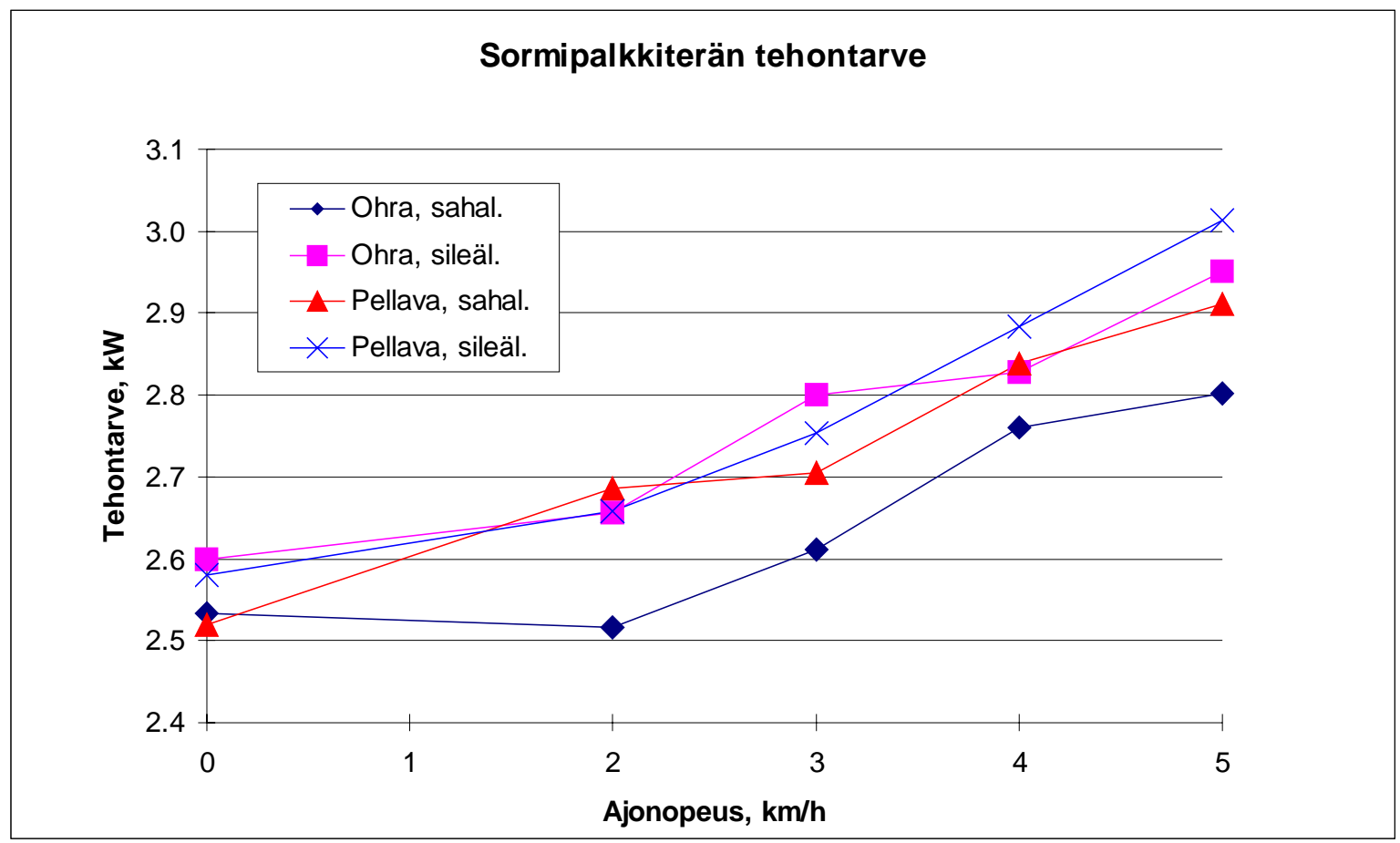

Kuva 3. Sormipalkkiterän tehontarve. Puitavana materiaalina oli öljypellavaa ja rehuohraa sekä käytössä oli kaksi eri terälapputyyppiä, hammastettu sekä sileälaitainen terälappu. Leikkuupöydän työleveys oli 12 jalkaa.

Kuvasta 3 havaitaan, että keskimääräinen tehontarve on noin $2,7 \ldots 2,8 \mathrm{~kW}$ ajonopeudesta riippuen. Työleveysmetriä kohden tämä on noin $0,8 \mathrm{~kW} / \mathrm{m}$. Ajonopeuden ja kasvuston vaikutukset ovat vähäiset tehontarpeen kehittymiseen, lisäksi terälapun tyypin vaikutus on hyvin vähäinen.

\section{Johtopäätökset}

Vannesahaterän etuina ovat edestakaisen liikkeen puuttuminen ja pienet leikkuulaitteesta aiheutuvat värähtelyt korjuukoneen muihin rakenteisiin. Tällöin voidaan saavuttaa suurempia teränopeuksia rakenteiden kestävyyden heikkenemättä. Perinteisellä sormipalkkiterällä ongelmana ovat suuret kitkavoimat, mutta etuna terän mekaaninen stabiilius. "Päättymättömän" terän ongelmat ovat juuri päinvastaiset. Vanne on mekaanisesti hyvin alhaisen taivutusjäykkyyden omaava rakenne, joka muuttaa muotoaan jo pienilläkin voimilla ja niiden stabiliteettiin on kiinnitettävä huomiota riittävästi tukirakenteita suunniteltaessa.

Nauhaterän leikkuunopeutta voidaan kasvattaa käytännössä rajatta ilman että mekaaniset värähtelyt tulevat ongelmaksi. Normaali sormipalkkiterä onkin leikkuupuimurin suurin värähtelynlähde kohlimien ja seulojen ohella. Lisäksi kokeissa puidulla vannesahatyypin terälaitteella on kevätkorjattua hamppua puitaessa saavutettu merkkejä sen toimivuudesta. Uuden terälaitteen tehontarve on noin $0,9 \mathrm{~kW}$ työleveysmetriä kohden, joka on suurempi verrattuna sormipalkkiterän tehontarpeeseen, joka on noin $0,8 \mathrm{~kW} / 1 \mathrm{~m}$. Saavutettu teränopeus uudella konstruktiolla on yli $20-$ kertainen verrattuna sormipalkkiterän nopeuteen. Täyden mittakaavan leikkuulaitekonstruktion parantamiseksi tulisi kiinnittää huomiota terän poikittaisvärähtelyjen minimointiin ja ohjautuvuuteen vastaterää vasten. Koelaitekonstruktiossa päädyttiin nykyisiin sormipareihin kompaktin rakenteen ja valmistusprosessin ja kustannusten minimoimiseksi. Tehontarve muodostuu sekä perinteisellä että uudella terämekaniikalla niin pieneksi, että sillä on esimerkiksi polttoaineenkulutuksessa vähäinen merkitys.

\section{Kirjallisuutta}

Pasila, A., Pehkonen, A., Lalli, J., Pehkonen, T., Sihvola, J. 1998. Kasvikuitueristeen tuotannon koneketju. Helsingin yliopisto, Maa- ja kotitalousteknologian laitos. Helsinki. 60 s. + liitteitä $8 \mathrm{~s}$. 